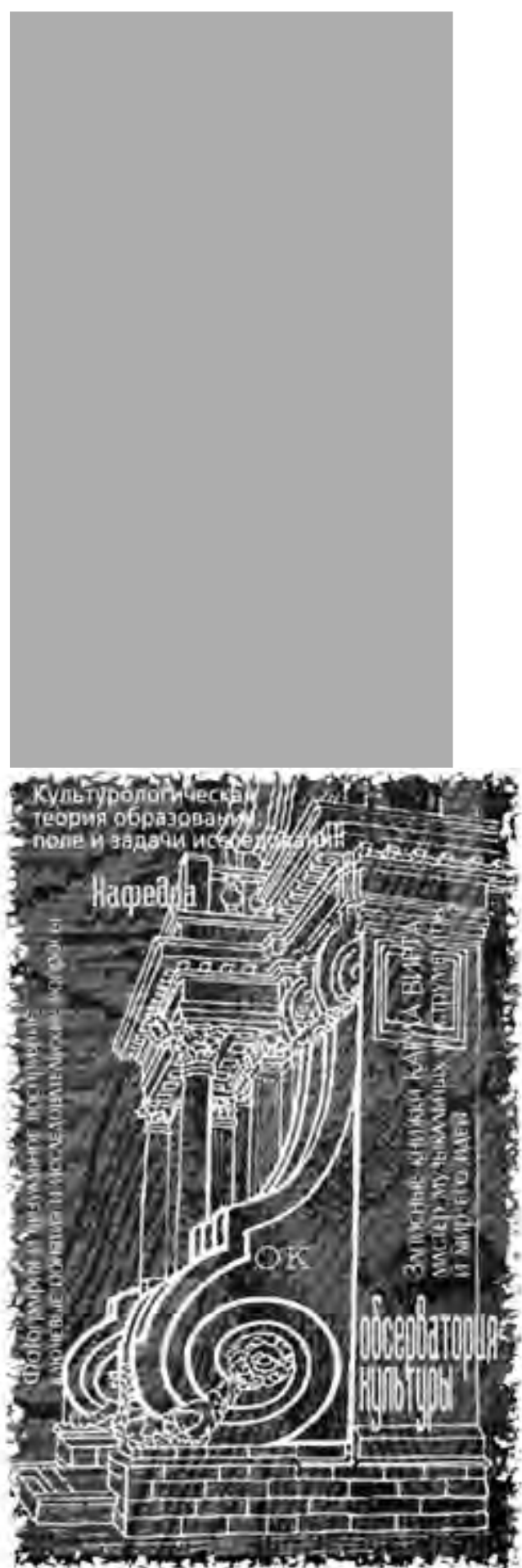

[ . . . лекции по культурологии] . . .

УДК 008:37.01

ББК 71.0

\title{
0.А. ЯнУтШ
}

\section{КУЛЬТУРОЛОГИЧЕСКАЯ ТЕОРИЯ ОБРАЗОВАНИЯ: ПОЛЕ И ЗАДАЧИ ИССЛЕДОВАНИЯ}

Исследуются проблемы, составляющие предметное поле новой области знания - культурологии образования. Автор обосновывает необходимость создания фундаментальной теории образования на основе метаметодического подхода, объединяющего принципы психологии, педагогики, философии образования и культурологии. Данная теория направлена на целостное изучение всех аспектов культурной политики и социокультурных практик повседневности, без корреляции с которыми невозможно выстроить эффективную модель развития системы образования. Ключевые слова: философия образования, культурология образования, личностно-ориентированное образование, философская антропология, социокультурные практики, государственная культурная политика.

C

мене культурных парадигм всегда сопутствовало повышение внимания к системе образования. Распространение и внедрение новых «моделей ментального пространства культуры» [1, с. 40] невозможно без переосмысления процессов обучения и воспитания нового типа личности, соответствующего аксиологическим, антропологическим и онтологическим сдвигам, происходящим в культуре или рассматриваемым в качестве идеала ее ближайшего развития.

В последние несколько десятилетий установки в определении задач образования в России сменялись трижды. Сначала традиционный «знаниевый» подход был заменен на «компетентностный». Приоритет стабильного и непротиворечивого самовоспроизводства культурных

\section{КАФЕДРА}


паттернов, свойственный советской системе образования, в условиях становящейся и развивающейся рыночной экономики сохраниться не мог. Для построения «нового» общества требовались люди, обладающие гибкой системой мышления и не столько строгой системой представлений, сколько хорошо отлаженным инструментарием (системой умений и навыков), легко интегрируемым в новые практики. На смену «компетентностному» пришел «адаптационный» подход, делающий акцент на формировании у учащихся способности адекватно реагировать на вызовы современной культуры и применять полученные знания и навыки в процессе социализации и инкультурации. Появление данного подхода стало логическим следствием принятия категории личного успеха (творческого, социального, финансового и пр.) в качестве базовой ценности поколения, выросшего в новых экономических условиях. Однако у многих исследователей вызывает тревогу постулирование в качестве одной из главных задач образования «превращение человека в субъекта социума и культуры» (см. напр.: [2, с. 70]). 0.И. Горяинова, например, полагает, что это полностью отдает человека во власть социальной необходимости, лишает его подлинной свободы и приводит к фрагментации единого поля деятельности личности [3]. Однако, специфика развития современной культуры делает практически невозможным создание прогностических моделей долгосрочной эволюции общества и, следовательно, соответствующих эффективных педагогических систем подготовки учащихся к жизни в этом будущем: «личности предстоит осваивать мир, спрогнозировать который весьма проблематично» [4, с. 25]. Реализация данного подхода уже привела к катастрофическим результатам: например, по данным исследования, проведенного ВЦИОМ в 2011 году, «треть опрошенных всерьез полагают, что Солнце вращается вокруг Земли (32\%), причем за последние четыре года таких респондентов стало даже больше (с $28 \%$ в 2007 году)» [5].

Как известно, существующая на данный момент система образования сформировалась на основе идеалов культуры Просвещения и была призвана решать задачи развития индустриального общества. Основным минусом этой системы была ориентация на стандартизированное обучение, готовящее усредненных представителей «рабочего класса», способных эффективно социализироваться лишь в рамках крупных корпораций с четко обозначенными сферами обязанностей и практиками поведения. Современная же экзистенциально-персонологическая парадигма образования исходит из смены соотношения между понятиями «свобода» и «необходимость» (в частности, «образование»), в смысле придания большей значимости первому из них [6]. В центре внимания оказывается задача формирования навыков конвергентного мышления, позволяющих личности не просто успешно интегрироваться в существующие социокультурные практики, но и создавать принципиально новые.

Вместе с тем, очевидные неудачи последних реформ в сфере образования и шквал общественной критики, который вызывают почти все новые идеи и предложения по ее реформированию, отчетливо свидетельствуют о необходимости поиска новой точки зрения, новой перспективы рассмотрения места и задач системы образования в современной культуре. Одним из его результатов стало появление новой научной области - культурологии образования.

На данный момент можно отметить несколько очень важных итогов внедрения культурологического подхода к образованию. Во-первых, это обращение к принципу культуросообразности, сформулированному еще А. Дистервегом и получившему развитие и реализацию в концепциях культуроориентированного, культуротворческого образования. Отбор содержания, выстраивание программ изучения отдельных предметов (или надпредметных циклов), выбор методов обучения осуществляется при этом, исходя из необходимости обеспечить возможность «самоопределения и самореализации человека в многокультурном и взаимосвязанном мире, наличие в его личностном арсенале способности к диалогу и толерантности и др.» [1, с. 39-40]. Во-вторых, особое внимание стало уделяться понятиям общекультурной и культурологической компетентности всех субъектов образовательного процесса (учащихся, их родителей, педагогического и административного состава школ). В-третьих, появилось большое количество исследований и конкретных проектов, рассматривающих особенности современной культурно-образовательной среды и культурно-образовательного пространства (школы, города, региона).

Однако в свете сложившейся ситуации, упомянутой в самом начале статьи, особую значимость на данный момент представляет разработка целостной культурологической теории образования как методологической базы исследований в области образования в целом - базы, строящейся на «изучении образования в контексте и в его многосторонней связи с социокультурным целым» $[1$, c. 39]. Задачи создания подобной теории видятся в определении тех проблем, которые необходимо решить на пути перехода от старой системы подготовки к новой, формулировке ряда принципиальных вопросов, без ответа на которые предлагаемые реформы останутся фрагментарными и паллиативными.

Первый блок проблем связан с определением принципов взаимосвязи образования как одной из ключевых подсистем культуры с другими подсистемами, прежде всего, социально-экономической и политической. Из истории образования прекрасно известно, насколько тесно связаны эти сферы, но для успешного реформирования современной системы образования необходим тщательный анализ принципов, активно «работающих» сейчас, и возможных последствий сохранения данной модели взаимодействия указанных подсистем в будущем. Например, один из наиболее очевидных процессов, происходящих в нашем обществе, - снижение коррелятивных связей между уровнем полученного образования и социальной «успешностью» человека. Получение образования даже в лучших вузах страны не гарантирует трудоустройства и достойного уровня жизни в случае работы по специальности, а количество специалистов, ежегодно выпускаемых высшими учебными 
заведениями, оказывается несоразмерным реальным запросам рынка труда. При этом престиж высшего образования остается на довольно высоком уровне, превратившись из прагматической ценности преимущественно в символическую. Принято либо просто констатировать это положение дел, либо предлагать варианты переструктурирования системы подготовки школьников и студентов, отдавая предпочтение ранней и более глубокой профессионализации. В действительности же, решение представляется невозможным без предварительного ответа на вопрос, должно ли образование обеспечивать определенный (высокий) уровень общей культуры всего населения страны или его задача предельно конкретна - подготовка кадров для определенных сфер производства? 0т того, каким будет ответ, зависит и содержание программ обучения, и специфика построения учебных планов, и методы обучения, и соотношение «бюджетных» и «платных» программ, и система взаимных обязательств государства и выпускников. От этого же зависит определение целей и задач каждой ступени образования.

В образовательной парадигме XX века линейная иерархическая преемственность в деятельности различных институтов образования являлась естественным инструментом выявления наиболее достойных учащихся, обладающих соответствующим установленным нормам и критериям потенциалом для перехода на следующую ступень и, как следствие, получавшим определенный высокий статус в обществе. C 60-80-х годов XX века в трудах отечественных и зарубежных ученых разрабатываются модели системы общего среднего образования, в которых главной задачей выступает формирование общей культуры личности и свободное развитие индивидуального потенциала каждого учащегося. Происходит смещение акцента с результата обучения на сам процесс обеспечения оптимального развития личности ребенка. В наиболее радикальном варианте это приводит к развитию «хоумскулинга» (обучения на дому по школьной программе) и «анскулинга» (свободного обучения на дому, вообще не привязанного к школьной программе), приверженцев которых во всем мире становится с каждым годом все больше. С одной стороны, этот процесс обусловлен отсутствием «соответствия между образованием и его антропологической основой <...> [практикой] педагогического насилия, подчинения целей учебно-воспитательной деятельности произволу субъективных интересов и беспочвенных педагогических фантазий» [7, с. 78]. С другой стороны - специфическим строем современных социокультурных практик и возможностями информационного пространства, благодаря которым индивидуальные запросы развития и последующую профессиональную (творческую) самореализацию личности становится проще обеспечить вне институтов государственного образования, нежели в них.

Такой личностно ориентированный подход, отвечающий высшим демократическим, гуманистическим и прочим ценностям, на самом деле содержит некоторые риски. Он предполагает довольно утопическую ситуацию, при которой:
- различные виды деятельности обладают одинаковым символическим статусом и обеспечивают примерно одинаковый финансовый достаток;

- люди, развиваясь каждый в соответствии с собственными врожденными талантами, формируют органичное целое, обеспечивающее эффективное и самодостаточное функционирование государства;

- в различных регионах страны одинаково возможно не только организовать такую систему образования, но и предоставить возможность в дальнейшем успешно работать в выбранной сфере.

К сожалению, во многих «развитых» странах, уважение к интеллектуальному труду часто сопровождается неуважением к любому другому. Молодых людей, мечтающих стать журналистами, актерами или фотографами, гораздо больше, чем тех, кто в идеале видит себя дворником, продавцом или ассенизатором. В результате обеспечить нормальное функционирование многих сфер жизни без мигрантов становится проблематичным, а количество «депрессивных регионов» растет.

Таким образом, проблема состоит в создании модели, достаточно универсальной для обеспечения высокой культуры нации (сохранения культурных традиций), достаточно вариативной, чтобы обеспечить индивидуальные запросы учащихся, полноценное и свободное развитие личности, а также способствующей выполнению заказа государства, обеспечивающей стабильное функционирование всех его систем. Решение этой, казалась бы, очевидной задачи связано с вопросом о мере соотношения личного и государственного блага, комфортной и успешной интеграции личности в существующий социокультурный контекст в долгосрочной перспективе развития страны в целом.

Второй блок проблем сопряжен с очевидным перераспределением образовательных функций между собственно учреждениями системы образования и другими социокультурными практиками и институтами. Влияние среды всегда играло важную роль в процессе формирования личности наряду с семьей и школой. Однако сейчас оно становится практически доминирующим. В современной культуре в целом представляется более уместным говорить о приоритете практик, а не институтов. Логоцентристская модель передачи культурных ценностей в значительной мере заменяется акционистской. Поэтому одним из аспектов культурологии образования должны стать анализ и проектирование воспитательного, развивающего, обучающего потенциала тех социокультурных практик, которые непосредственно влияют на развитие личности. Такое расширение границ оправдано в силу смещения ядра образовательного процесса из четко организованного и контролируемого института в поле свободного самоопределения личности. И здесь, как ни странно, особое внимание должно быть уделено социокультурным практикам «взрослых» и принципам государственной культурной политики в целом. Важно отметить, что речь идет не только и не столько о специальных программах «образования взрослых», сколько о системе практик повседневности. 
Одна из серьезнейших проблем нашего общества полное делегирование задачи формирования и развития личности ребенка школе, которая, по сути, воспринимается как специфический инкубатор, замкнутая и изолированная система. Значение семьи и окружающей среды рассматривается обычно на уровне констатации. Или же, что встречается еще чаще, они фигурируют в качестве «заказчика» и «общественного контролера всех этапов образовательного процесса»: «Креативная модель предполагает открытый и общественный характер образования, где заказчиком является гражданское общество, а государство - преимущественно, организатор и гарант качества и доступности образования» [8]. Закрепление за гражданским обществом статуса потребителя, а не активного субъекта образовательного процесса (причем не на этапе обсуждения и отбора содержания, а в непосредственной длительности реализации данного процесса) представляется симптоматичным и тревожащим фактом. По большому счету речь идет о неготовности общества взять на себя ответственность за определенные стороны развития детей.

Простой пример: можно сколь угодно долго говорить в школе о необходимости толерантного отношения к людям с ограниченными возможностями, но пока не будут созданы условия для свободного перемещения таких людей по улицам города, посещения различных институтов культуры, в частности тех же школ детьми-инвалидами, то есть условия для ведения полноценной жизни, для учащихся все эти разговоры останутся отвлеченными «красивыми словами», никак не связанными с их реальной жизнью и соответствующими моделями поведения. Другой пример: постоянно говорят о том, что дети перестают читать «серьезную» литературу, не интересуются искусством и пр. При этом, «величина среднесуточной аудитории телевидения (выраженная в показателях охвата количество человек, включивших телевизор) колеблется в интервале $80 \%-75 \%$ населения» [9], а «свободное время большинство россиян предпочитает проводить дома. Светские виды досуга, такие, например, как походы в кино, театр, бары или ночные клубы, увлекают совсем небольшую часть наших сограждан» [10], «отдыхать с книгой любят только треть опрошенных (27 \%). Причем большинство предпочитает легкое чтиво: детективы и фантастику» [11]. Впрочем, по данным исследований, в последние годы происходит сокращение телеаудитории, причем как раз за счет молодежи (15-30 лет). И в этом можно было бы увидеть некоторую положительную динамику, если бы значительная часть этой молодежи не обращалась к другим источникам информации (Интернет, медиа), продолжая при этом отдавать предпочтение материалам, аналогичным по содержанию и художественному уровню тем, которые транслирует телевидение.

Таким образом, в данном аспекте задачей культурологической теории образования является выстраивание дифференцированного и многоуровневого пространства диалога между различными ступенями образования, субкультурами и институтами культуры, а также создание механизмов включения субъектов культуры любого воз- раста в различные практики, способствующие обучению, воспитанию и развитию личности.

Наконец, третий блок проблем связан с исследованием современного детства и юношества. Трансформация культуры оказывает наибольшее влияние именно на подрастающее поколение, определяя специфику не только аксиологической системы, но и самих мыслительных практик. При сохранении базовых законов развития психики наблюдаются значительные изменения в формировании и протекании психологических процессов. Развиваясь на стыке психологии и философской антропологии, культурологические исследования данного направления позволяют иначе взглянуть на развитие человека в современном обществе. Практики выстраивания взаимодействия между субъектами культуры меняются, как в диахроническом, так и в синхронистическом срезах. Если XX век можно назвать предельно «детоцентрированным», подчинявшим все силы родителей (и общества) обеспечению информативного и эмотивного заполнения жизни ребенка, то в начале XXI века эти связи стремительно трансформируются. Во-первых, современные технологии используют преимущественно «интуитивный интерфейс» - систему управления, которой не надо обучаться, ее можно освоить опытным путем за пару минут. При этом родители часто оказываются не в состоянии помочь, наоборот, сами просят у детей помощи при встрече с новыми «гаджетами», ресурсами и сервисами сети Интернет. В результате, происходит формирование установки на эмпирическое, а не рациональное постижение действительности, имеет место девальвация опыта предыдущих поколений. Во-вторых, постоянная и одновременная загруженность всех каналов восприятия, свойственная пребыванию в современном информационном пространстве, раньше и сильнее развивает у детей склонность к решению многофакторных задач. Это позволяет охватывать более широкие пласты информации, но часто ведет и к ее обесцениванию. Возможность полного контроля над виртуальными мирами и свободного доступа к любым необходимым данным и программам (фоторедакторы, программы для создания музыки и видео, он-лайн переводчики и пр.) формирует навыки стратегического мышления. При этом, как отмечает И.Б. Романенко, «онтологическое вопрошание истины подменяется навязыванием формального смысла, поиск сущности - обнаружением возможного ответа из нескольких предложенных» [6, с. 63]. Однако стоит признать и тот факт, что выбор такой стратегии поведения свойственен современным молодым людям только в ситуациях, обладающих для них низким личностным значением. Решение многофакторных задач связано с наделением каждого фактора определенным коэффициентом значимости, и выбор самого простого (и поверхностного) пути решения одной, по каким-то причинам необходимой, подзадачи освобождает больше времени и сил для другой, личностно значимой. И вот тут подростки и молодые люди в полной мере проявляют свои творческие способности (будь то компьютерная игра или открытие собственного бизнеса). 
Сложившаяся ситуация, со всеми её плюсами и минусами, вызывает опасения не только в силу возможных негативных последствий для физического и психического здоровья нового поколения. Поскольку человек - ключевое звено культуры, изменения в интеллектуальной и эмоциональной сферах его жизни и деятельности формируют специфическую систему характеристик принципиально нового субъекта культуры. Следовательно, особенно важными представляются анализ и разработка компенсаторных механизмов, нивелирующих возможные риски, связанные с особенностями данного типа субъекта для развития культуры в целом. Можно выделить два основных момента, вызывающих наибольшие опасения. Во-первых, психологи отмечают у современных детей снижение способности к распознаванию эмоционального состояния окружающих, причин, вызвавших данное состояние, и способов соответствующего реагирования, навыков управления собой и взаимодействия с окружающими. Соответственно, принципиальные изменения коммуникативных способностей происходят как в вертикальной плоскости (о чем уже говорилось выше), так и в горизонтальной. Во-вторых, на фоне возрастания числа образовательных и развивающих программ для дошкольников и младших школьников в нашем обществе «отсутствует доверие к растущим людям, выведение их за пределы узко детских дел и забот. Ребенок, подросток, реально поднимающийся на новый уровень социальной зрелости, не включается всерьез, последовательно в сферу деятельности общества» [12, с. 11]. Итогом данных тенденций становится замена полноценного диалога (в широком философском смысле слова) простым информационным обменом. Нельзя не согласиться с тем, что полное подчинение образования актуальным культурным практикам, привычным для ребенка или подростка, обеспечивает ему некоторый психологический комфорт и успешную социализацию. Но, как представляется, в долгосрочной перспективе это может привести к постепенной редукции поля возможных трансформаций культуры, к ограничению возможности ее полноценного, вариативного и многонаправленного развития и, в конечном счете, к стагнации.

Последние конференции, посвященные комплексу вопросов, рассмотренных в данной статье, свидетельствуют о принципиальных расхождениях и все возрастающем дистанцировании во взглядах представителей педагогики, философии образования и культурологии. Причина этого заключается, видимо, в том, что при едином «объекте» изучения, «предметы» находятся в принципиально разных плоскостях. Новая перспектива исследования, предлагаемая культурологией образования, строится на метаметодическом единстве подходов, используемых в упомянутых научных областях при анализе проблем образования: «ученик - специфика изучаемого предмета - желаемый результат обучения/ воспитания» (педагогика), «человек - образование как феномен и как процесс - предельные основания культуры и бытия» (философия) и «субъект культуры система образования - пространство культуры» (культурология). Таким образом, на данный момент основная цель культурологии образования видится в определении единой логики, методологии и категориального аппарата анализа, экспертизы и проектирования различных компонентов системы образования. Другими словами, - в построении фундаментальной теории образования как одной из наиболее сложных и значимых социокультурных практик современности. Теории, в отсутствие которой дальнейшее реформирование системы образования в лучшем случае вряд ли будет успешным, в худшем может вызвать еще больший кризис.

\section{Список литературы}

1. Мосолова Л.М. 0 задачах новой школы в контексте культурологии // Universum: Вестник герценовского университета. - 2011. — № 5.

2. Алексеева Т.Б. Культурологический подход в современном образовании: Научно-методическое пособие. - СПб.: 000 «Книжный дом», 2008.

3. Горяинова О.И. Личность и образование в культурных проектах модерна и постмодерна // Личность в социокультурном измерении: история и современность. - М.: Индрик, 2007.

4. Токарев С.Н. Культурологические аспекты содержания школьного гуманитарного образования // Universum: Вестник герценовского университета. - 2011. - № 5.

5. ВЦИОМ: Всероссийский центр изучения общественного мнения. Пресс-выпуск №1684 [Электронный ресурс]. - Режим доступа: http://wciom.ru/index.php?id=459\&uid=111345

6. Романенко И.Б. Экзистенциализм и персонализм: определение образовательных идеалов XXI века // Известия российского государственного педагогического университета им. А.И. Герцена. - 2005. - № 5.

7. Стрельченко В.И. Философия и педагогика. // Известия российского государственного педагогического университета им. А.И. Герцена. - 2002. - № 2.

8. Вuдт И.Е. Образование как феномен культуры: эволюция образовательных моделей в историко-культурном процессе: автореф. дис. ... д-ра пед. наук. - Тюмень, 2003.

9. Полуэхтова И.А. Социокультурная динамика российской аудитории телевидения: автореф. дис. ... д-ра социологических наук. - М., 2008 // Библиотека авторефератов и тем диссертаций [Электронный ресурс]. - Режим доступа: http://dibase.ru/article/22092008_poluekhtovaia/4

10. ВцИОМ: Свободное время россияне отдают телевизору // ВцИом [Электронный ресурс]. - Режим доступа: http://wciom.ru/index.php?id=266\&uid=9191

11. ВЦИОМ: Россиянам недосуг // ВЦИОМ [Электронный ресурс]. - Режим доступа: http://wciom.ru/index. php?id=266\&uid $=10230$

12. Фельдштейн Д.И. Сущностные особенности современного детства и задачи теоретико-методологического обеспечения процесса образования // Педагогика. - 2009. - № 1. 